\title{
DIGITALCOMMONS
}

@WAYNESTATE —

Wayne State University

Kinesiology, Health and Sport Studies

College of Education

$10-1-2015$

\section{Psychometric Properties of the Abbreviated Perceived Motivational Climate in Exercise Questionnaire}

\author{
E. Whitney G. Moore \\ University of North Texas, whitneymoore@wayne.edu \\ Theresa C. Brown \\ University of Kansas \\ Mary D. Fry \\ University of Kansas
}

\section{Recommended Citation}

Moore, E. W. G., Brown, T. C., \& Fry, M. D. (2015). Psychometric properties of the abbreviated perceived motivational climate in exercise questionnaire. Measurement in Physical Education and Exercise Science, 19(4), 186-199. doi: 10.1080/1091367X.2015.1072819 Available at: http://digitalcommons.wayne.edu/coe_khs/60 
Psychometric Properties of the Abbreviated Perceived Motivational Climate in Exercise Questionnaire

\section{E. Whitney G. Moore}

Kinesiology, Health Promotion, and Recreation, University of North Texas, Denton, Texas

Theresa C. Brown and Mary D. Fry

Department of Health, Sport \& Exercise Science, University of Kansas, Lawrence, Kansas 


\begin{abstract}
The purpose of this study was to develop an abbreviated version of the Perceived Motivational Climate in Exercise Questionnaire (PMCEQ-A) to provide a more practical instrument for use in applied exercise settings. In the calibration step, 2 shortened versions' measurement and latent model values were compared to each other and the original PMCEQ using a 3-group CFA invariance testing approach with previously collected exercise setting data $(N=5,427)$. Based on the model fit and reliability values, the 12 -item version performed better than the 17 -item version. The resultant 12-item PMCEQ-A's CFA model estimates were then compared to the PMCEQ's model values for 2 different, previously conducted studies of exercise settings $(N=$ 414 and 770). The more parsimonious 12-item PMCEQ-A can be used by exercise psychology researchers to gain insight into members' perspectives on the motivational climate and may lead to developing effective strategies to enhance members' experiences and commitment.
\end{abstract}

Keywords: motivational climate, exercise, task-involving, ego-involving, Achievement Goal Perspective Theory 
Psychometric Properties of the Abbreviated Perceived Motivational Climate in Exercise

\section{Questionnaire}

Although the benefits of regular physical activity are well known and documented, a large portion of the adult population remains sedentary, so identifying ways to increase exercise behaviors is a worthwhile and needed area of study (Shuval et al., 2013). Fitness center environments provide an ideal location to promote exercise as part of a healthy lifestyle, but unfortunately they can be intimidating places for individuals (Miller \& Miller, 2010). Emerging research in the field of exercise psychology has shown the benefits of fostering a task-involving over an ego-involving climate to enhance individuals' motivational responses and likelihood of commitment to an exercise program (Brown \& Fry, 2013; Brown, Fry, \& Little, 2013; Hogue, Fry, Fry, \& Pressman, 2013; Huddleston, Fry, \& Brown, 2012; Moore \& Fry, 2014). The Perceived Motivational Climate in Exercise Questionnaire (PMCEQ; Huddleston et al., 2012), a tool for measuring perceptions of the climate, was developed; however, the 27-item instrument's length can be problematic for applied researchers who wish to maximize the participant pool by minimizing respondent burden. Therefore, the need exists for a shorter scale measuring perceptions of the climate in exercise settings.

The literature on motivational climate in exercise settings is based on achievement goal perspective theory (AGPT), as conceptualized by Nicholls $(1984 ; 1989)$. Nicholls identified that individuals could perceive the motivational climate in achievement settings as being task- or egoinvolving. In a task-involving climate, individuals perceive their best efforts are encouraged, personal improvements are emphasized, cooperation is fostered, and everyone plays an important role. Conversely, in an ego-involving climate individuals perceive that superior ability is recognized and valued, and negative attention is drawn to those who make mistakes (Newton, 
Duda, \& Yin, 2000).

Nicholls was interested in maximizing the motivation of individuals in achievement settings. He suggested that leaders in achievement settings are in a prime position to influence individuals' motivation by shaping the participants' definitions of success. While the motivational climate research has been more systematically applied to sport and physical education settings (e.g., Iwasaki \& Fry, 2013; Papaioannou, Marsh, \& Theodorakis, 2004; Wang, Liu, Chatzisarantis, \& Lim, 2010), a growing number of researchers have argued for its application to extend to exercise and fitness settings as well (Brown \& Fry, 2014a; Brown et al., 2013; Hogue et al., 2013; Huddleston et al., 2012; Moore \& Fry, 2014). Researchers have argued that staff in fitness settings are similar to physical education teachers and coaches in their opportunities to work with participants - thereby influencing members' future commitment to physical activity (Brown \& Fry, 2011, 2014; Huberty et al., 2008). Fitness center staff can use language and actions that help individuals focus on their own effort and improvement and deemphasize normative standards (Brown \& Fry, 2011; Huberty et al., 2008). Brown and Fry (2014) found that fitness facility members' perceptions of the staff's positive and supportive behaviors correlated with the members' perceptions of the facility's climate as caring and taskinvolving. Given the opportunities for interaction, exercise leaders and fitness center staff can help participants set and shape their fitness-related goals.

Huddleston and colleagues (2012) were among the first to apply the motivational climate framework to a fitness center by investigating corporate fitness members' perceptions of their exercise facilities. Although several instruments exist in the motivational climate literature that are specific to sport (i.e., Perceived Motivational Climate in Sport Questionnaire, Perceived Motivational Climate in Sport Questionnaire-2, and Motivational Climate Scale for Youth 
Sports), not all the items on the sport-specific instruments are relevant to exercise and fitness (Newton et al., 2000; Smith, Smoll, \& Cumming, 2007; Walling, Duda, \& Chi, 1993). Therefore, as a suitable instrument did not exist for the exercise context, Huddleston and colleagues modified the existing Perceived Motivational Climate in Sport Questionnaire-2 (PMCSQ-2; Newton et al., 2000), which was an instrument originally created to measure athletes' perceptions of the motivational climate in sport settings. The resultant PMCEQ was a multidimensional 27item scale that measured participants' perceptions of two identified constructs (i.e., task- and ego-involving climates) in exercise settings. The PMCEQ has been used in several research studies considering the motivational climate in exercise settings and demonstrated statistical integrity with moderate to high CFA factor loadings, Cronbach's alpha values above .70, and significant relationships of expected magnitude and direction with a variety of different outcome constructs — including caring climate, commitment, ownership in exercise, empowerment in exercise, and satisfaction with life (Brown \& Fry, 2013; Brown \& Fry, 2014b; Brown et al., 2013; Hogue et al., 2013; Huddleston et al., 2012; Moore \& Fry, 2014).

Despite the promise of the PMCEQ, its length makes it cumbersome; thus, a shorter scale that measures perceptions of the climate in exercise settings is desired. As the PMCEQ is typically included with additional measures of psychosocial constructs—-such as individuals' exercise behaviors, enjoyment, and motivation; and more global measures, such as individuals' psychological well-being - the surveys can quickly become lengthy. By diminishing the PMCEQ's items, one or more different scales could be included within the original length of the PMCEQ. A short form could decrease the total survey length, which could decrease participant fatigue and increase data quality (Graham, Olchowski, \& Gilreath, 2007; Little et al., 2014). In addition, the repetitiousness of some items could be removed, which may also decrease 
participant fatigue. Marsh and colleagues (2005) provided guidelines when determining the need for a short form of an existing psychological measure. The guidelines recommend that researchers start by selecting a strong instrument, grounded in a sound theory. The PMCEQ was promising, developed from a respected theoretical base and psychometrically sound (Huddleston et al., 2012).

Marsh and colleagues (2005) go on to suggest several guidelines that must be met for the short form to be a viable alternative instrument. Their recommendations expanded on those provided by Smith, McCarthy, and Anderson (2000) on the development of short-form evaluation tools. Marsh and colleagues (2005) suggested that items should measure the same factors on the long and short forms, the responses to both the short and long instruments should be stable over time, and age and gender differences should be consistent across both versions. These guidelines help operationalize the short form development process and require that data from both long form and short form versions of the instrument be compared in a multitude of ways.

For applied researchers, in addition to choosing valid and reliable tools, the length of time to administer and score a chosen instrument is an important consideration. Therefore, the purpose of this study was two-fold: (a) to identify an abbreviated version of the PMCEQ (PMCEQ-A), by employing a confirmatory factor analysis (CFA) and structural equation model (SEM) framework to calibrate it with the PMCEQ, and (b) to use data from two different exercise settings to validate the PMCEQ-A measurement of the task- and ego-involving climates. The PMCEQ-A constructs were hypothesized to match the full-version PMCEQ ${ }^{1}$ constructs' measurement invariance and to replicate the latent descriptive statistics to provide support for

\footnotetext{
${ }^{1}$ For the rest of the paper the original PMCEQ is designated PMCEQ-27 for clarity.
} 
both the reliability and validity of the abbreviated measure.

\section{Method}

Data from three independently collected samples were used for this study. Sample 1 was used to compare three different versions of the PMCEQ (Study 1) whereas Samples 2 and 3 were used to validate the performance of the best version of the PMCEQ-A with theoretical constructs of interest (Study 2). Approval for each of these studies was obtained from the Institutional Review Board at the researchers' university, and consent was obtained from the participants (all 18 years of age and over). Participants in all three samples reported their gender and age or grade in college. Each sample was collected as a larger, independent study, so only two or three constructs per sample were used for model parsimony during validity testing. Each sample is specifically described below.

\section{Participants}

Study 1. Participants of Study $1(N=5,427 ; 92 \%$ female $)$ were U.S. members of an international exercise franchise with a predominantly female membership. The current U.S. members were sent a link to the researchers' survey and given one month to complete the online survey. Individuals completed an online consent form prior to starting the survey. Sample 1's large sample size allowed us to create three smaller datasets $(N=500)$, one for each PMCEQ version, randomly drawn without replacement. This dataset was part of a larger study (Brown \& Fry, 2014a; Moore, Brown, \& Fry, 2011); therefore, only the participants' responses to the PMCEQ-27, the Caring Climate Scale (CCS), and the Ownership in Exercise Scale (OES) were used for concurrent validity testing.

Study 2. Sample 2 participants ( $N=414 ; 68 \%$ female) were enrolled in the semester-long 
physical activity classes offered at a large Midwestern university. These classes included a variety of activities such as individual and team sports, as well as weight training and aerobics. Participants completed hardcopy surveys during their regular class period at the end of the semester, while their instructor was absent from the room. This data came from a larger study (Brown \& Fry, 2013; Moore \& Fry, 2014), so participants' responses to the PMCEQ-27, the CCS, the OES, and the Subjective Happiness Scale were used for concurrent validity testing. Sample 3 participants $(N=770 ; 51 \%$ female) were members of the student recreation center at a large Midwestern university. The researchers provided university students multiple opportunities to voluntarily complete the hardcopy survey. This dataset was part of a larger study (Brown, Fry, \& Little, 2013), and only participants' responses to the PMCEQ-27, the CCS, and the Commitment to Exercise Scale were modeled.

\section{Measures}

Perceived Motivational Climate in Exercise Questionnaire (PMCEQ-27). The PMCEQ-27 was developed by Huddleston, Fry, and Brown (2012) to assess participants' perceptions of the task- and ego-involving features of the motivational climate in exercise settings. The researchers first used the measure to examine members' perceptions of the climate in a corporate fitness center. This 27 -item measure is comprised of 14 task-involving items and 13 ego-involving items. The task-involving items capture the following characteristics of the climate: participants believe that best effort and personal improvement are emphasized, cooperation is fostered among participants, and everyone is valued and welcomed in the setting. In contrast, the ego-involving items characterized the following: participants believe that only the best are noticed, they feel a sense of rivalry among others, and they feel self-conscious or embarrassed if they do not know how to perform an exercise or how to use a piece of equipment. 
Sample items were, "In this facility, members feel successful when they improve" (task) and "In this facility, members are hesitant/embarrassed to ask the staff or other members for help" (ego). Participants responded to the items using a 5-point scale ranging from 1 (strongly disagree) to 5 (strongly agree).

Support for the PMCEQ-27's constructs exists in prior research, with reliability values ranging from .84 to .90 , and consistently correlate with concurrent validity constructs in theoryhypothesized directions and magnitudes (Brown et al., 2013; Hogue et al., 2013; Huddleston et al., 2012; Moore \& Fry, 2014). For example, Huddleston et al. (2012) found a task-involving climate to be significantly positively correlated with exercise enjoyment $(r=.38)$, competence $(r$ $=.31)$, and effort $(r=.32)$; whereas, an ego-involving climate was significantly, negatively correlated with enjoyment $(r=-.26)$, competence $(r=-.36)$, and effort $(r=-.32)$.

Caring Climate Scale (CCS). The CCS (13-items) was developed to measure participants' perceptions of caring characteristics in exercise and fitness settings. A sample CCS item is "In this facility, members are treated with respect." Participants responded to the items with a 5-point scale ranging from 1 (strongly disagree) to 5 (strongly agree). The CCS has consistently demonstrated strong measurement reliability, .92 to .96 , and been associated with concurrent validity constructs in theory-hypothesized directions and magnitudes (Gano-Overway et al., 2009; Newton et al., 2007). For example, Newton et al. (2007) found the caring climate to have a moderate, positive correlation with the task-involving climate $(r=.56)$ and a moderately small, negative correlation with the ego-involving climate $(r=-.36)$. In this study, the average variance extracted (AVE, criterion value of .50; Fornell \& Larcker, 1981) and the composite reliability (CR, criterion value of .60; Hair, Anderson, Tatham, \& Black, 1998) were used to assess measurement reliability. The CCS' measurement of the caring climate was shown to meet 
these reliability criterion in Study $1(\alpha=.90, \mathrm{AVE} \geq .66, \mathrm{CR} \geq .85)$ and Study 2 , Sample $2(\alpha=$ $.93, \mathrm{AVE} \geq .67, \mathrm{CR} \geq .86)$ and Sample $3(\alpha=.93, \mathrm{AVE} \geq .55, \mathrm{CR} \geq .83)$

Ownership in Exercise Scale (OES). The 5-item OES was recently developed to measure the extent that participants perceive they have ownership of their exercise class experience (Moore \& Fry, 2014). A sample ownership item is "The instructor gave me opportunities to modify movements/intensities." Participants in Sample 1 and Sample 2 responded to the items with a 5-point scale ranging from 1 (strongly disagree) to 5 (strongly agree). This scale showed good reliability (McDonald's coefficient omega $=.90$ ) and concurrent validity relationships in theory-hypothesized directions and magnitudes (Moore \& Fry, 2014). For example, Moore and Fry (2014) reported that ownership was predicted by task-involving ( $b^{*}$ $=.37)$ and ego-involving $\left(b^{*}=-.15\right)$ climates and that ownership predicted empowerment in exercise $\left(b^{*}=.29\right)$. The OES measured ownership reliably in the current Study $1(\alpha=.93$, AVE $\geq .54, \mathrm{CR} \geq .85)$ and Study 2 , Sample $2(\alpha=.83, \mathrm{AVE} \geq .47, \mathrm{CR} \geq .81)$.

Subjective Happiness Scale (SHS). The 4-item Subjective Happiness Scale (Lyubomirsky \& Lepper, 1999) was employed in Sample 2 to assess individuals' overall happiness in life. A sample item is "In general, I am ..." (1) not a very happy person to (7) a very happy person. Participants chose from the seven response options. This scale was shown to have good reliability (Cronbach's alpha coefficient $=.86$ ) and has received psychometric support through its relationships with concurrent validity constructs (Lyubomirsky \& Lepper, 1999). For example, Lyubomirsky and Lepper, (1999) found subjective happiness to be moderately positively correlated with individuals' reported self-efficacy $(r=.53)$ and optimism $(r=.53)$. In this study, the happiness construct was measured reliably in Study 2, Sample $2(\alpha=.79$, AVE $\geq$ $.55, \mathrm{CR} \geq .82)$. 
Commitment to Exercise (CES). The 5-item Commitment to Exercise Scale (Alexandris, Zahhraiadis, Tsorbatzoudis, \& Grouios, 2002) was developed to measure individuals' commitment to continue their exercise routines in the future. Sample 3 participants responded to the CES with a Likert scale ranging from 1 (not at all) to 5 (extremely). A sample item is "How dedicated are you to exercising?" This scale has consistently been a reliable (Cronbach's alpha coefficient $=.86)$ and valid measure of individuals' future commitment to exercise (Alexandris et al., 2002; Brown \& Fry, 2013). Brown and Fry (2013) found commitment to exercise to have a small, positive correlation with perceiving a task-involving climate and a small, negative correlation with perceiving an ego-involving climate. In addition, this study's Study 2, Sample 3 reliability values supported that commitment $(\alpha=.82$, AVE $\geq .55, \mathrm{CR} \geq .83)$ was measured reliably.

\section{Item Reduction Approach}

We developed two short versions of the PMCEQ to compare to the original 27-item instrument in order to determine the shortened set of items that best represented the original constructs. Given that having fewer items reduces the representative area that can be measured for a construct, our goal was to select items that represented the nomological net of the construct's respective characteristics. Thus, we (all AGPT researchers) reviewed the original instrument's items independently to determine those that represented each construct's target characteristics, were most clearly written, and were not redundant. Then we compared their independent lists. If we did not agree an item should be included, we discussed items further until consensus was reached. By the end of this process, 17 items were selected for one version of a shortened PMCEQ to be tested against the PMCEQ-27 informed constructs.

After developing the 17-item PMCEQ scale, we used the same independent review 
process to determine the 12 items (i.e., 6 task- and 6 ego-involving) that best represented the characteristics of the motivational climate. We selected a 12-item measure because it would allow for two items to measure each characteristic for the respective climates, while still reducing the overall measure by approximately $55 \%$. We agreed upon a minimum of two items per climate characteristic (e.g., see parcels depicted in Table 1) to maintain the measurement design of the PMCEQ, which measures the influence of both the instructor and the peer group on the participants' perceptions of the motivational climate (Brown, 2006; Little, 2013). Thus, the content validity of the original measure was maintained in both the 17- and 12-item versions. Working from the already agreed upon 17-item PMCEQ, we compared our updated independent lists, and discussed any disagreement on items to cut, until consensus was reached on the five additional items that could be removed in order to create a 12 -item version. Both the 12- and 17item versions were evaluated for understanding and clarity by a team of graduate students studying exercise psychology.

\section{Data Analyses}

The datasets used for these analyses had been tested for normalcy prior to this study being conducted. Each dataset contained minimal missingness (less than 7\%), which was handled either by utilizing FIML (full-information maximum likelihood; Sample 1 and Sample 2) or MI (multiple imputation, $m=100$; Sample 3), based upon which modern approach to handling missing data was utilized with the data originally. Use of either FIML or MI is the currently accepted best practice when there is minimal missing data and when that missingness is not due to a missing-not-at-random process (Graham et al., 2007; Little, Jorgensen, Lang, \& Moore, 2013). All confirmatory factor analysis (CFA) models were conducted using Mplus 7.0 (Muthen \& Muthen, 1998-2012). 


\section{Calibrating the PMCEQ-A (Study 1)}

First, we used Sample 1's data to run an item-level configural model for both the 12-item and 17-item PMCEQ versions to assess their respective model fits. Model fit was assessed by the chi-square test statistic, CFI, NNFI, RMSEA, and SRMR. The following values were used as baselines for adequate model fit, CFI and NNFI $\geq .90$, RMSEA and SRMR $\leq .08$ (Brown, 2009; Cheung \& Rensvold, 2002; Hu \& Bentler, 2002; Little, 2013). Second, we parceled the items by their respective facets (i.e., characteristics; See Table 1) to create three parcels loading onto the task- and ego-involving climates, respectively, as part of a three-group analysis. Each group utilized a different PMCEQ version (12-, 17-, and 27-items) to inform the task- and egoinvolving parcels (Little, 2013; Little, Cunningham, Sharar, \& Widaman, 2002; Little, Rhemtulla, Gibson, \& Schoemann, 2013).

Parceling was an important aspect of the measurement analysis. One, it ensured the number of degrees of freedom were the same for each model. Two, it made the assessment of the measurement model constraints (i.e., weak invariance) truly comparable because there were no individual items in the larger models that could "absorb" model misfit; thereby incorrectly implying that the constraints were equatable (Brown, 2006; Little, 2013). By having the same degrees of freedom and directly testing the constraints placed on the same parcels, if information was significantly missing from the fewer item models, then this would be revealed through either (a) failing a model constraint, (b) change in the pattern of loadings or intercepts, or (c) the presence of large modification indices—another sign of model misfit (Brown, 2006; Little, 2013).

The models were specified by the fixed factor method. Therefore, the variance of each latent variable was fixed to 1.0. This standardized the factor loadings and equated the variances 
across the groups (Brown, 2006; Little, 2013). We then assessed the constraints for weak and strong invariance, homogeneity of variances, covariances, and means across the 12-item, 17item, and 27-item PMCEQ groups. The tenability of the weak and strong invariance constraints was passed with a change in CFI $\leq .01$ (Cheung \& Rensvold, 2002). These invariance constraints compared the shortened versions' measurement models against the 27-item measurement model. The homogeneity of the groups' latent variances, covariances, and means were then tested to examine the shortened versions' ability to accurately capture the descriptive statistics of the respective climate variables (Little, 2013). The nested models chi-square difference test was used to assess the tenability of each of these parameters' values being constrained to equality across the PMCEQ versions.

To assess the success at maintaining the reliability of the constructs' measurement through this item reduction process, the reliability of the PMCEQ-A and PMCEQ-27 scales were calculated including Cronbach's alpha, AVE, and CR. Essentially, the latter reliability statistics represent the ratio of true score variance to total score variance for a specific construct based upon the factor loadings that are available when a CFA is conducted. Therefore, the AVE and CR are appropriate when a CFA is conducted (Kline, 2007). The Cronbach's alpha values are also presented for the PMCEQ versions, using the traditional criterion of .70 for acceptable reliability (Tabachnick \& Fidell, 2007). Given that fewer items comprise the shortened measure, a decrease in reliability compared to the full PMCEQ-27 would not be unexpected, particularly because maintaining validity with fewer items was prioritized over maintaining the most similarly worded items. Therefore, the expectation was that the PMCEQ-A would have lower but similar internal reliability values and present the same pattern of facet factor loadings.

\section{Validating the PMCEQ-A (Study 2)}


Once we determined the most efficient shortened version of the PMCEQ (i.e., PMCEQA), additional support for the PMCEQ-A constructs' behavior matching the PMCEQ-27 constructs' behavior was assessed across gender — both at the measurement and structural model levels and with different validity constructs in the structural model. We ran two-group (i.e., gender) CFA models utilizing the PMCEQ-A and PMCEQ-27 parceling schemes in Study 2 with Sample 2 and Sample 3 data, which resulted in two separate (i.e., PMCEQ-A and PMCEQ-27), two-group (i.e., gender) models run with each dataset. The two respective models were tested for measurement invariance across gender (i.e., weak and strong invariance) and homogeneity of latent variances, covariances, and means across gender. These model results were used to assess the ability of the PMCEQ-A parceling scheme to accurately capture the factor loadings and descriptive statistics (i.e., means, standard deviations, and correlations) of the task- and egoinvolving climates' constructs compared to the PMCEQ-27's respective parameter values. Therefore, we tested the ability of the PMCEQ-A to produce the same model parameters as the PMCEQ-27 when fit to Sample 2's and Sample 3's data.

\section{Results}

\section{Study 1: Calibration of the PMCEQ-A to the PMCEQ-27}

We assessed measurement model invariance using Sample 1's data to confirm that each underlying latent construct was still being equivalently represented when fewer items were used. Configural models using the 12-, 17-, and 27-item versions of the PMCEQ were all run (see Table 5). The 12-item PMCEQ had the best model fit. Then we parceled the items for each model by characteristic, and the three versions were modeled as different groups within a threegroup CFA. We did this so that the factor loadings and intercepts for the parcels using the 12item and 17-item PMCEQ versions could be directly tested for measurement invariance with the 
matching PMCEQ-27 parcels' loadings and intercepts. This three-group configural model showed acceptable model fit $(\mathrm{CFI}=.94, \mathrm{NNFI}=.92, \mathrm{SRMR}=.051, \mathrm{RMSEA}=.087[95 \% \mathrm{CI}$ : $.082-.093])$. We found the weak invariance model—constraining the parcel loadings to be equal across the three version groups - to be tenable $(\Delta \mathrm{CFI}=.002)$. Next, we also found strong invariance, constraining the parcel means to be equal across the three version groups, to be tenable $(\triangle \mathrm{CFI}=.01)$. The shortened versions of the PMCEQ passing the measurement invariance tests with the original PMCEQ-27 confirmed that the underlying latent constructs, task- and egoinvolving climates, were being equivalently represented by the 12 - and 17 -item versions.

The next step was to assess the latent parameters (i.e., variances, covariances, and means) to ensure that they were also being appropriately captured by the shortened versions (see Table 2). First, the latent variances and covariances passed the homogeneity test $\left(\Delta \chi^{2}=45.25, p=\right.$ .001 ), indicating that the latent variances for each construct - as well as the covariances between task-involving, ego-involving, caring, and ownership in exercise - were all constrainable across all questionnaire versions. These latent relationships were in theoretically expected directions and magnitudes, with the task-involving climate being moderately positively correlated with caring, and strongly positively correlated with ownership in exercise. On the other hand, the egoinvolving climate was moderately negatively correlated with caring, and strongly negatively correlated with ownership in exercise. Second, the latent means were constrained to be equatable across the three measures to assess the homogeneity of the means reproduced by the shortened versions of the PMCEQ compared to the original PMCEQ. This omnibus of homogeneity of the latent means across measures was passed $\left(\Delta \chi^{2}=8.83, p=.357\right)$. Thus, the latent means were being reproduced equivalently by both shortened versions compared to the PMCEQ-27.

These homogeneity test findings provided validity support for the 12-item PMCEQ 
representing the task- and ego-involving climates' variability, average, and latent cross-sectional relationships with two other latent constructs. Additionally, the factor loading patterns were the same for the 12- and 27-item PMCEQ parcels in the Sample 1 weak invariance test. As the aim of this study was to determine the most parsimonious scale, while maintaining quality, we selected the 12-item version as the PMCEQ-A to be further validated in Study 2 with Samples 2 and 3. Therefore, the follow-up comparison models were completed with just the new PMCEQA (i.e., 12-items) and the original PMCEQ (i.e., PMCEQ-27). See Table 1 for the PMCEQ and PMCEQ-A items.

\section{Reliability Estimates of the PMCEQ-A}

The passage of the measurement invariance tests supported that the measurement qualities of the different versions were equatable; therefore, the respective latent constructs were representing the same comparable construct. The reliabilities of the PMCEQ-A version revealed similar patterns to the PMCEQ values - their factor loading patterns were also matching. Specifically, the PMCEQ-A task-involving climate met the reliability criterion with all three samples based upon the AVE (.51-.82), CR (.76-.93), and Cronbach alpha (.77-.79) values. The PMCEQ-A ego-involving climate did not meet the reliability criterion in all three sample models based upon the AVE (.30-.55), but it did present the same pattern of AVE values as the PMCEQ-27 ego-involving climate (AVE = .39-.59). The PMCEQ-A ego-involving climate did meet the composite reliability criterion $(\mathrm{CR}=.70-.78)$ in all but one model $(\mathrm{CR}=.53)$, and again it followed the same pattern as the PMCEQ-27 ego-involving climate values. Lastly, the egoinvolving alpha values met the .70 reliability criterion across all three samples by both the PMCEQ-A (.72-.80) and the PMCEQ (.88-.90).

More specifically, Study 1, Sample 1's task-involving reliability values for the PMCEQ 
$(\mathrm{AVE} \geq .64, \mathrm{CR} \geq .84, \alpha=.89)$ and PMCEQ-A (AVE $\geq .51, \mathrm{CR} \geq .76, \alpha=.77)$ and egoinvolving for the PMCEQ (AVE $\geq .59, \mathrm{CR} \geq .81, \alpha=.89$ ) and the PMCEQ-A (AVE $\geq .55, \mathrm{CR} \geq$ $.78, \alpha=.80$ ) presented similar patterns. Study 2 , Sample 2's task-involving reliability values for the PMCEQ (AVE $\geq .71, \mathrm{CR} \geq .88, \alpha=.90)$ and PMCEQ-A (AVE $\geq .53, \mathrm{CR} \geq .77, \alpha=.72)$ and ego-involving for the PMCEQ (AVE $\geq .39, \mathrm{CR} \geq .63, \alpha=.90$ ) and the PMCEQ-A (AVE $\geq .30$, $\mathrm{CR} \geq .53, \alpha=.72$ ) presented similar patterns. The PMCEQ-A model fit the Sample 2's data as well as or better than the PMCEQ-27 model throughout the CFA (see Table 6), indicating that the relationships present in the data were being better represented by the PMCEQ-A model. In addition, Study 2, Sample 3's constructs all met the criterion for reliability. Specifically, taskinvolving climate values for the PMCEQ (AVE $\geq .70, \mathrm{CR} \geq .88, \alpha=.89$ ) and PMCEQ-A (AVE $\geq .58, \mathrm{CR} \geq .80, \alpha=.78$ ) and ego-involving climate for the PMCEQ (AVE $\geq .54, \mathrm{CR} \geq .76, \alpha=$ $.88)$ and the PMCEQ-A (AVE $\geq .45, \mathrm{CR} \geq .70, \alpha=.72)$ presented similar patterns. Therefore, the overall reliability evidence (i.e., measurement invariance, plus AVE, CR, and Cronbach's alpha values) taken together across all three samples for the PMCEQ-A supports that the items comprising the two climate scales do reliably measure exercise participants' task- and egoinvolving climate perceptions, and do so in a manner that maintains the validity of the latent constructs when directly compared to the original PMCEQ constructs.

\section{Study 2: Validation of the PMCEQ-A to the PMCEQ-27}

Sample 2. In order to assess the quality of the measurement model across gender for the PMCEQ-A in relation to the original PMCEQ-27, we ran two gender CFA models with the data from Sample 2-first with the PMCEQ-27 parcels and then with the PMCEQ-A parcels. Overall, the reliability values supported the PMCEQ-A constructs' internal structure. Specifically, the PMCEQ-A met configural, weak, and strong invariance constraints across genders with the same 
modifications necessary as the PMCEQ-27 (i.e., we freed one residual correlation and the Rival parcel's intercept). These results support that the measurement model using the PMCEQ-A represented Sample 2's data in the same manner as the measurement model using the PMCEQ27. The partial strong invariance model fit for the PMCEQ-A $(\mathrm{CFI}=.95, \mathrm{NNFI}=.93, \mathrm{RMSEA}=$ $.062)$ was slightly better than for the PMCEQ-27 (CFI $=.94$, NNFI $=.92$, RMSEA $=.069)$.

Once the CFA measurement model was established, the next step was to test the models' homogeneity of variances, covariances, and means. Sample 2's models had the same significance results with respect to the tenability of these model constraints. Both the PMCEQ-27 and the PMCEQ-A models required the inclusion of phantom constructs, after the ego-involving climate's variance was found to be significantly greater for males $\left(S D_{P M C E Q}=1.70, S D_{P M C E Q-A}=\right.$ $1.78)$ than for females $\left(S D_{P M C E Q}=1.00, S D_{P M C E Q-A}=1.00\right)$. Both models also revealed significantly higher ego-involving mean reports by males $\left(M_{P M C E Q}=1.95, M_{P M C E Q-A}=1.95\right)$ compared to females $\left(M_{P M C E Q}=1.59, M_{P M C E Q-A}=1.58\right)$. The PMCEQ-A final model fit the data better $(\mathrm{CFI}=.95, \mathrm{NNFI}=.94, \mathrm{RMSEA}=.061)$ than the PMCEQ-27 final model $(\mathrm{CFI}=.94$, NNFI $=.92$, RMSEA $=.068)$. Lastly, we examined the final PMCEQ-A and PMCEQ-27 models' latent parameters to determine if the relationships between the constructs were similarly represented for Sample 2 (Table 3). For example, the latent correlations from the males' report of the ego-involving climate with the task-involving climate was identical, whereas the magnitude was very similar in the females' models. The ego-involving climate's correlation values with caring, ownership, and happiness were very similar in the two male models and the two female models. Very similar correlation values were also seen for the males' and the females' taskinvolving climate's correlations with caring, ownership, and happiness. These results further support that the PMCEQ-A model's latent parameters behaved similarly to the PMCEQ-27 
model.

Sample 3. The PMCEQ-A model also fit Sample 3's data as well as or better than the PMCEQ-27 model throughout the CFA. Specifically, the PMCEQ-A met configural, weak, and strong invariance constraints across genders with nearly the same change in CFI as the PMCEQ27 (See Table 7). These results provided additional evidence that the PMCEQ-A was measuring the same underlying latent constructs as the PMCEQ-27, and that there were no significant measurement differences across genders with these items.

In addition, Sample 3's models both passed the homogeneity of variances, covariances, and means tests. For example, task-involving means were similar based on the male ( $M_{P M C E Q}=$ $\left.3.34, M_{P M C E Q-A}=3.38\right)$ and female $\left(M_{P M C E Q}=3.31, M_{P M C E Q-A}=3.35\right)$ reports, as were the egoinvolving means for the males $\left(M_{P M C E Q}=3.03, M_{P M C E Q-A}=2.97\right)$ and females $\left(M_{P M C E Q}=3.05\right.$, $\left.M_{P M C E Q-A}=2.83\right)$. The task- and ego-involving climates' correlation values were also similar based on the male and female reports (Table 4). The females' reported a moderate positive correlation between the caring and task-involving climates, and a weak positive correlation with commitment to exercise that were similar for both the PMCEQ and PMCEQ-A. In addition, the males' reported weak negative correlations for the ego-involving climate with the caring climate and commitment to exercise that were nearly identical values from the PMCEQ and PMCEQ-A models. The PMCEQ-A final model fit $(\mathrm{CFI}=.998, \mathrm{NNFI}=.998, \mathrm{RMSEA}=.012)$ was comparable to the PMCEQ-27 final model fit $(\mathrm{CFI}=.994, \mathrm{NNFI}=.993, \mathrm{RMSEA}=.023)$. These results further support that the PMCEQ-A model's latent parameters behaved similarly to the PMCEQ-27 model. Taken together, the PMCEQ-A model represented the data similarly to the PMCEQ-27 model and fit the data slightly better.

Thus, the results from Study 2 provided validity support for the ability of the PMCEQ-A 
to not only measure the underlying latent constructs equivalently, but to also represent the taskand ego-involving climate constructs' relationships with each other and with other constructs equivalently to a model utilizing the PMCEQ-27 measured constructs. Thus, the PMCEQ-A is a shorter, more parsimonious measure of the same task- and ego-involving climate constructs.

\section{Discussion}

The purpose of this study was to develop an abbreviated version of the PMCEQ-27, an instrument originally created to assess participants' perceptions of the task- or ego-involving climate in exercise settings. The results from Study 1 and Study 2 provide support for the use of the PMCEQ-A as a shorter, equivalent measure of exercise participants' perceptions of task- and ego-involving motivational climates. By shortening the length of the PMCEQ by 15 items, researchers and practitioners have more room within a survey to include additional outcome variables or to shorten the length of time required by participants to complete the survey; this can result in a greater quality of data collected when the PMCEQ-A is used (Graham et al., 2007). Although applied researchers may understand the necessity for shortened instruments to better entice potential participants, the practice of developing short forms is not without critics (Marsh et al., 2005; Smith et al., 2000). Therefore, in an effort to avoid unnecessary truncation of existing instruments, Marsh et al. (2005) proposed a number of guidelines to follow when creating a short form, several of which are used to frame this discussion.

Marsh and colleagues (2005) argued that first, a strong instrument must be selected and measures must be taken to ensure the short version retains the content coverage for each factor measured. They also proposed that the short form should retain the factor structure of the original form. The original PMCEQ was derived from a strong theoretical base (Nicholls, 1984; 1989), modeled after a proven instrument specific to sport settings (PMCSQ and PMCSQ-2; Newton et 
al., 2000; Seifriz, Duda, \& Chi, 1992; Walling et al., 1992), and used in a wide variety of exercise settings such as group fitness classes, campus recreation centers, corporate fitness centers, and international exercise franchisees (Brown et al., 2013; Brown \& Fry, 2013; Brown \& Fry, 2014b; Hogue et al., 2013; Moore, Brown \& Fry, 2011). When choosing the best items to represent the task- and ego-involving climate on the PMCEQ-A, the definitions established by Huddleston and colleagues (2012) were used as a guiding framework to ensure that all conceptualized components of each climate's nomological net were represented by the items selected. The invariance of the factor structure when the original PMCEQ-27 was compared to the two different shorter versions demonstrated that the content coverage was successfully maintained by the fewer item measures. The latent means, variances, and covariances with concurrent constructs (caring and ownership) were reproduced equivalently by both shortened versions compared to the PMCEQ-27, supporting the decision to adopt the shortest version (i.e., 12-item PMCEQ) for further testing.

Marsh and colleagues (2005) also suggested that each factor on the shortened version of the instrument should be adequately reliable. Using the AVE and CR criteria to assess measurement reliability, the present study compared original PMCEQ-27 and PMCEQ-A reliability values' magnitudes and patterns. The AVE and CR criterion values were met across all three samples for the task-involving climate when measured by the PMCEQ-27 and the PMCEQA. The AVE criterion was not met across all three samples for the ego-involving climate; however, the same pattern was evident for both the original and shortened instruments. In addition, the ego-involving climate measurement did meet the CR and Cronbach's alpha criterion by both the PMCEQ-27 and PMCEQ-A. Therefore, the overall reliability evidence suggests that the items on the PMCEQ-A adequately represent the two different climates. 
Finally, although Marsh and colleagues (2005) acknowledged that each factor of the newly created short form could be shown to have validity in an independent sample, they also argued that this particular criteria may be better met by accumulating results from on-going research rather than relying on the results of one study. They also argued that reanalysis of existing data comparing the long form and short form with parallel analyses should be a central component of the creation of a short version (Marsh, Martin, \& Jackson, 2010). In line with their guidelines, we considered two additional independent samples of previously collected data to test whether relationships between constructs remained. Both samples reproduced the same correlation values for all latent relationships, regardless of which version of the PMCEQ was used. This provides evidence that the PMCEQ-A's climate measures maintained the concurrent validity of the PMCEQ-27. The current study provides initial validity evidence from three independently collected samples, which, in congruence with Marsh et al.'s suggestions, will continue to be built through researchers' use and continued testing of the short form's psychometric properties with future independently collected data samples.

The creation and validation of the PMCEQ-A, as described in this current study, offers several strengths. First, by relying on previously collected data, we were able to cross-validate the newly created instrument using a variety of demographic markers including gender, age (i.e., college-aged vs. adult), and type of exercise setting, while simultaneously demonstrating that the PMCEQ-A performed as well as the original version. Second, advanced missing data techniques (e.g., multiple imputations, full information maximum likelihood) were used to handle missingness in the chosen samples, further ensuring that all data informed the measurement process (Graham et al., 2007; Little, 2013; Little et al., 2013). Third, large data sets were chosen to allow for sophisticated data design utilizing CFA multi-group model testing to directly 
compare the equitability of the PMCEQ-A measurement and latent model estimates to the PMCEQ values. Finally, a number of exercise motivational outcomes - caring, ownership, happiness, and commitment to exercise — were selected for this study to add to the concurrent validity strength of the PMCEQ-A, demonstrating that the PMCEQ-A adequately represent the relationships not only between the task- and ego-involving climates, but also between known correlates of these motivational climates in exercise (Brown \& Fry, 2014b; Moore \& Fry, 2014).

However, despite these strengths, there are limitations to the study's results. Original data collection with the PMCEQ-A is now needed. The quality of the PMCEQ-A's estimates, compared to data collected with the PMCEQ from a random sub-sample of the study's participants, supported the quality of the properties of the abbreviated PMCEQ. The expectation would be that the quality of the PMCEQ-A data would be of at least the same quality, or higher, than the PMCEQ data. A second limitation was the lack of longitudinal data and analysis with the PMCEQ-A. Such longitudinal data would provide stability estimates for the task- and egoinvolving constructs measured by the PMCEQ-A, and would also advance the field's understanding of the impact exercise settings' motivational climate has on exercise-related outcomes.

The present investigation provides support for the psychometric properties of the PMCEQ-A, an instrument that could be of value to applied researchers interested in the motivational climate in exercise settings. The PMCEQ-A is an instrument that is adequately reliable, yields similar correlational patterns when compared to the full version, and is a more reasonable length. This last point is critical to future researchers examining the short- and longterm effects of exercise settings' motivational climates on participants' motivational responses, including effort, commitment to continue exercising, and empowerment to be physically active, 
healthy individuals. Answering these important questions can necessitate the inclusion of several measurement tools to assess the impact of motivational climates in exercise settings. Given the continually increasing physical inactivity rates internationally, decreasing the burden on research participants by using the PMCEQ-A will increase researchers and practitioners ability to assess the quality and impact of motivational climates in exercise settings. Thus, the addition of the PMCEQ-A to the literature enables researchers to continue to apply the AGPT theoretical framework across a diverse range of exercise participants.

\section{References}

Alexandris, K. P., Zaharaiadis, C., Tsorbatzoudis, C., \& Grouios, G. (2002). Testing the sport commitment model in the context of exercise and fitness participation. Journal of Sport Behavior, 25(3), 217-30.

Brown, T. A. (2009). Confirmatory factor analysis for applied research. New York, NY: The Gilford Press.

Brown, T. C, \& Fry, M. D. (2011). Helping members commit to exercise: Specific strategies to impact the climate at fitness centers. Journal of Sport Psychology in Action, 2(2), 70-80. doi:10.1080/21520704.2011.582803.

Brown, T. C., \& Fry, M. D. (2013). Association between females' perceptions of college aerobic class climates and their motivational responses. Women \& Health, 53, 843-857. doi:10.1080/03630242.2013.835298

Brown, T. C., \& Fry, M. D. (2014a). Motivational climate, staff and members' behaviors, and members' psychological well-being at a national fitness franchise. Research Quarterly for Exercise and Sport, 85(2), 1-10. doi:10.1080/02701367.2014.893385

Brown, T. C., \& Fry, M. D. (2014b). College exercise class climates, physical self-concept, and 
psychological well-being. Journal of Clinical Sport Psychology, 8(3), 299-313.

Brown, T. C., Fry, M. D., \& Little, T. D. (2013). The psychometric properties of the Perceived Motivational Climate in Exercise Questionnaire. Measurement in Physical Education and Exercise Science, 17(1), 22-39. doi:10.1080/1091367x.2013.741360

Cheung, G. W., \& Rensvold, R. B. (2002). Evaluating goodness-of-fit indexes for testing measurement invariance. Structural Equation Modeling, 9(2), 233-255. doi:10.1207/S15328007SEM0902_5

Fornell, C., \& Larcker, D. F. (1981). Evaluating structural equation models with unobservable variables and measurement error. Journal of Marketing Research, 18, 39-50. doi:10.2307/3151312

Gano-Overway, L. A., Newton, M., Magyar, T. M., Fry, M. D., Kim, M., \& Guivernau, M. R.(2009). The influence of caring youth sport contexts on efficacy-related beliefs and social behaviors. Developmental Psychology, 45(2), 329-340. doi:10.1037/a0014067

Graham, J. W., Olchowski, A. E., \& Gilreath, T. D. (2007). How many imputations are really needed? Clarifications of multiple imputation theory. Prevention Science, 8, 206-213. doi:10.1007/s11121-007-0070-9

Hair, J. F. Anderson, R. E., Tatham, R. L., \& Black, W. C. (1998). Multivariate data analysis with readings (5th ed.). Upper Saddle River, NJ: Prentice Hall.

Hogue, C. M., Fry, M. D., Fry, A. C., \& Pressman, S. D. (2013). The influence of a motivational climate intervention on participants' salivary cortisol and psychological responses. Journal of Sport \& Exercise Psychology, 35(1), 85-97.

Hu, L., \& Bentler, P. M. (1999). Cutoff criteria for fit indexes in covariance structure analysis: Conventional criteria versus new alternatives. Structural Equation Modeling, 6(1), 1-55. 
doi:10.1080/10705519909540118

Huberty, J. L., Ransdell, L. B., Sidman, C., Flohr, J. A., Shultz, B., Grosshans, O., \& Durrant, L. (2008). Explaining long-term exercise adherence in women who complete a structured exercise program. Research Quarterly for Exercise and Sport, 79(3), 374-384. doi:10.1080/02701367.2008.10599501

Huddleston, H., Fry, M. D., \& Brown, T. C. (2012). The relationship between perceived motivational climate and intrinsic motivation in corporate wellness environments. Revista de Psicologia del Deporte, 21(1), 18-23.

Iwasaki, S., \& Fry, M. D. (2013). The efforts of sport psychology professionals to assist sport administrators in evaluating youth sport programs, The Sport Psychologist, 27, 360-371.

Kline, R. B. (2007). Chapter 7: Measurement Models and Confirmatory Factor Analysis. In: Principles and practice of structural equation modeling (2nd ed.). New York, NY: The Gilford Press.

Little, T. D. (2013). Longitudinal structural equation modeling. New York, NY: The Gilford Press.

Little, T. D., Cunningham, W. A., Shara, G., \& Widaman, K. F. (2002). To parcel or not to parcel: Exploring the question, weighing the merits. Structural Equation Modeling, 9(2), 151-173. doi:10.1207/S15328007SEM0902_1

Little, T. D., Jorgensen, T. D., Lang, K. M., \& Moore, E. W. G. (2014). On the joys of missing data. Journal of Pediatric Psychology, 39(2), 151-162. doi:10.1093/jpepsy/jst048.

Little, T. D., Rhemtulla, M., Gibson, K., \& Schoemann, A. M. (2013). Why the items versus parcels controversy needn't be one. Psychological Methods, 18(3), 285. doi:10.1037/a0033266 
Lyubomirsky, S., \& Lepper, H. S. (1999). A measure of subjective happiness: Preliminary reliability and construct validation. Social Indicators Research, 46, 137-155. doi:10.1023/A:1006824100041

Marsh, H. W., Ellis, L. A., Parada, R. H., Richards, G., \& Heubeck, B. G. (2005). A short version of the Self Description Questionnaire II: Operationalizing criteria for short-form evaluation with new applications of confirmatory factor analyses. Psychological Assessment, 17(1), 81-102. doi:10.1037/1040-3590.17.1.81

Marsh, H. W., Martin, A. J., \& Jackson, S. (2010). Introducing a short version of the Physical Self Description Questionnaire: New strategies, short-form evaluative criteria, and applications of factor analyses. Journal of Sport \& Exercise Psychology, 32, 438-482.

Miller, W. C., \& Miller, T. A. (2010). Attitudes of overweight and normal weight adults regarding exercise at a health club. Journal of Nutrition Education and Behavior, 42(1), 2-9. doi:10.1016/j.jneb.2008.08.005

Moore, E. W. G., Brown, T. C., \& Fry, M. D. (2011, October). National exercise facility's motivational climate effects symposium. Paper presented at the National Association of Applied Sport Psychology (AASP) Conference, Waikiki, HI.

Moore, E. W. G., \& Fry, M. D. (2014). Support for the Ownership in Exercise and Empowerment in Exercise Scales. Measurement in Physical Education and Sport Science, 18(2), 1-17. doi:10.1080/1091367X.2013.875472

Muthén, L. K., \& Muthén, B. O. (1998-2012). Mplus user's guide (7th ed.). Los Angeles, CA: Muthén \& Muthén.

Newton, M., Duda, J. L., \& Yin, Z. (2000). Examination of the psychometric properties of the Perceived Motivational Climate in Sport Questionnaire-2 in a sample of female athletes. 
Journal of Sports Sciences, 18, 275-290. doi:10.1080/026404100365018

Newton, M., Fry, M. D., Watson, D. L., Gano-Overway, L. A., Kim, M., Magyar, M. T., \& Guivernau, M. R. (2007). Psychometric properties of the Caring Climate Scale in a physical activity setting. Revista de Psicologia del Deporte. 16(1), 67-84.

Nicholls, J. G. (1984). Achievement motivation: Conceptions of ability, subjective experience, task choice and performance. Psychological Review, 91, 328-346. doi:10.1037/0033$295 x .91 .3 .328$

Nicholls, J. G. (1989). The competitive ethos and democratic education. Cambridge, MA: Harvard University Press.

Papaioannou, A., Marsh, H. W., \& Theodorakis, Y. (2004). A multilevel approach to motivational climate in physical education and sport settings: An individual or a group level construct? Journal of Sport \& Exercise Psychology, 26(1), 90-119.

Seifriz, J. J., Duda, J. L., \& Chi, L. (1992). The relationship of perceived motivational climate to intrinsic motivation and beliefs about success in basketball. Journal of Sport and Exercise Psychology, 14, 375-391.

Shuval, K., Hébert, E. T., Siddiqi, Z., Leonard, T., Lee, S. C., Tiro, J. A., McCallister, K., \& Skinner, C. S. (2013). Impediments and facilitators to physical activity and perceptions of sedentary behavior among urban community residents: The fair park study. Preventing Chronic Disease, 10, 1-7. doi:10.5888/pcd10.130125.

Smith, G. T., McCarthy, D. M., \& Anderson, K. G. (2000). On the sins of short-form development. Psychological Assessment, 7, 300-308. doi:10.1037//1040-3590.12.1.102

Smith, R. E., Smoll, F. L., \& Cumming, S. P. (2007). Effects of a motivational climate intervention for coaches on young athletes' sport performance anxiety. Journal of Sport 
PMCEQ-ABBREVIATED

\& Exercise Psychology, 29, 39-59.

Tabachnick, B. G., \& Fidell, L. S. (2007). Using Multivariate Statistics (5th ed.). Boston, MA: Pearson.

Walling, M. D., Duda, J. L., \& Chi, L. (1993). The Perceived Motivational Climate in Sport Questionnaire: Construct and predictive validity. Journal of Sport and Exercise Psychology, 15, 172-183.

Wang, J. C. K., Liu, W. C., Chatzisarantis, N. L. D., \& Lim, C. B. S. (2010). Influence of perceived motivational climate on achievement goals in physical education: A structural equation mixture modeling analysis. Journal of Sport \& Exercise Psychology, 32(3), $324-338$. 
1 Table 1

2 PMCEQ and PMCEQ-A (bold) Items and Parcel factor loadings (standardized)

\begin{tabular}{|c|c|c|c|c|c|c|}
\hline \multirow{2}{*}{$\begin{array}{l}\text { 1a. Task-involving climate parcels } \\
\text { Task-involving climate - Parcel 1: }\end{array}$} & \multicolumn{3}{|c|}{$\begin{array}{l}\text { Sample } 1 \\
\text { 27-item 17-item 12-item }\end{array}$} & \multirow{2}{*}{\multicolumn{3}{|c|}{\begin{tabular}{lccc}
\multicolumn{2}{l}{ Sample 2 } & \multicolumn{2}{l}{ Sample 3 } \\
27-item & 12-item & 27-item & 12-item \\
$.77 / .85$ & $.76 / .90$ & $.71 / .71$ & $.71 / .71$ \\
\end{tabular}}} \\
\hline & .75 & .77 & .77 & & & \\
\hline \multicolumn{7}{|c|}{$\begin{array}{l}\text { task2: members of all fitness levels are made to feel valued. } \\
\text { task5: all members feel welcome. } \\
\text { task6: members help each other learn. } \\
\text { task11: the instructor/staff encourages members to help each other. } \\
\text { task15: members really work together as a team. } \\
\text { task16: members help each other to get better and excel. }\end{array}$} \\
\hline Task-involving climate - Parcel 2: & .82 & .78 & .69 & $.84 / .85 .72 / .81$ & $.80 / .81$. & $80 / .81$ \\
\hline \multicolumn{7}{|c|}{$\begin{array}{l}\text { task3: members feel good when they try their best. } \\
\text { task10: members are rewarded and noticed when they try hard. } \\
\text { task12: the instructor/staff emphasizes always trying your best. } \\
\text { task13: members are encouraged to work on their weaknesses. }\end{array}$} \\
\hline Task-involving climate-Parcel 3: & .83 & .67 & .66 & $.91 / .88$ & $.76 / .75$ & $.76 / .75$ \\
\hline
\end{tabular}

\begin{tabular}{|c|c|c|c|c|c|c|c|}
\hline \multirow[t]{2}{*}{ 1b. Ego-involving climate parcels } & \multicolumn{3}{|c|}{ Sample 1} & \multicolumn{2}{|c|}{ Sample 2} & \multicolumn{2}{|c|}{ Sample 3} \\
\hline & 27-item & 17-item & 12-item & 27-item & 12-item & 27-item & 12-item \\
\hline Ego-involving climate - Parcel 1: & .68 & .66 & .66 & $.57 / .71$ & $.47 / .63$ & $.52 / .52$ & $.52 / .52$ \\
\hline
\end{tabular}




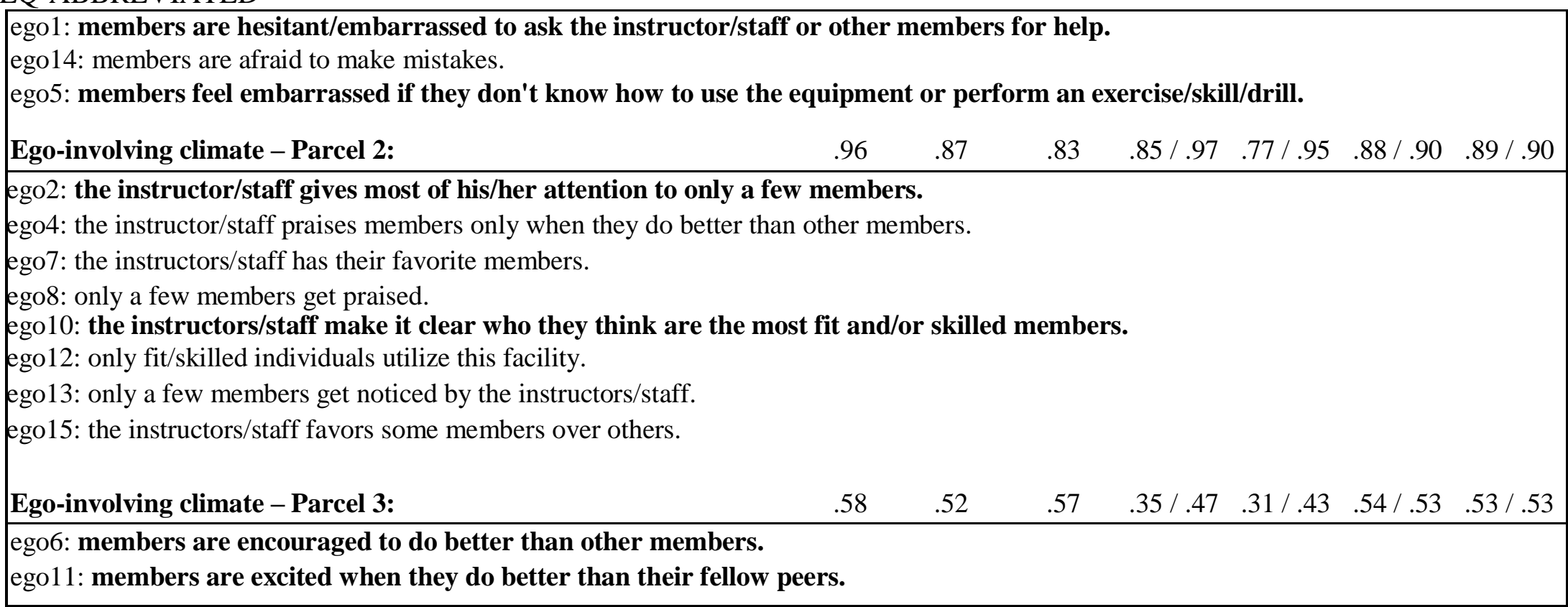

Note. The standardized loadings are presented for Sample 2 and Sample 3 from the female, and then male models.

\section{Table 2}

Sample 1 Standardized, Unconstrained Variances and Correlations

\begin{tabular}{|c|c|c|c|c|c|c|c|c|c|c|c|c|}
\hline \multirow[b]{3}{*}{ Task-involving climate } & \multicolumn{3}{|c|}{ Task-involving climate } & \multicolumn{3}{|c|}{ Ego-involving climate } & \multicolumn{3}{|c|}{ Caring climate } & \multicolumn{3}{|c|}{ Ownership in exercise } \\
\hline & 27-items & 17-items & 12-items & 27-items & 17-items & 12-items & 27-items & 17-items & 12-items & 27-items & 17-items & 12-items \\
\hline & $(.86)$ & $(.84)$ & $(1.0 *)$ & & & & & & & & & \\
\hline Ego-involving climate & -.52 & -.59 & -.53 & $(.55)$ & $(.59)$ & $\left(1.0^{*}\right)$ & & & & & & \\
\hline Caring climate & .41 & .53 & .45 & -.50 & -.49 & -.55 & (.78) & $(1.01)$ & $(1.0 *)$ & & & \\
\hline Ownership in exercise & .71 & .78 & .77 & -.69 & -.72 & -.63 & .51 & .53 & .50 & (.78) & $(.84)$ & $(1.0 *)$ \\
\hline Means & 4.02 & 4.1 & 4.06 & 1.78 & 1.84 & 1.85 & 4.61 & 4.59 & 4.63 & 4.27 & 4.28 & 4.29 \\
\hline
\end{tabular}

Note. The values in parenthesis are the variances for each construct in each group. The asterisk by the 12-items' variances designates that they were fixed to 1.0 to set the scale for the construct across the models. 
Table 3

Sample 2 Standardized, Unconstrained Variances and Correlations

\begin{tabular}{|c|c|c|c|c|c|c|c|c|c|c|}
\hline & \multicolumn{2}{|c|}{ Task-involving climate } & \multicolumn{2}{|c|}{ Ego-involving climate } & \multicolumn{2}{|c|}{ Caring climate } & \multicolumn{2}{|c|}{ Ownership in exercise } & \multicolumn{2}{|c|}{ Happiness } \\
\hline & 27-items & 12-items & 27-items & 12-items & 27-items & 12-items & 27-items & 12-items & 27-items & 12-items \\
\hline \multirow{2}{*}{ Task-involving climate } & $(1.10)$ & $(1.26)$ & \multirow{3}{*}{$\begin{array}{c}-.37 \\
(1.71) \\
\end{array}$} & \multirow{3}{*}{$\begin{array}{r}-.37 \\
(1.81) \\
\end{array}$} & \multirow{2}{*}{.62} & \multirow{2}{*}{.59} & \multirow{2}{*}{.65} & \multirow{2}{*}{.63} & \multirow{2}{*}{.27} & \multirow{2}{*}{.23} \\
\hline & $\left(1.0^{*}\right)$ & $\left(1.0^{*}\right)$ & & & & & & & & \\
\hline \multirow{2}{*}{ Ego-involving climate } & \multirow{2}{*}{-.53} & \multirow{2}{*}{-.57} & & & \multirow{2}{*}{-.38} & \multirow{2}{*}{-.36} & \multirow{2}{*}{-.32} & \multirow{2}{*}{-.33} & \multirow{2}{*}{-.03} & \multirow{2}{*}{-.08} \\
\hline & & & $\left(1.0^{*}\right)$ & $\left(1.0^{*}\right)$ & & & & & & \\
\hline \multirow{2}{*}{ Caring climate } & \multirow{2}{*}{.62} & \multirow{2}{*}{.68} & \multirow{2}{*}{-.71} & \multirow{2}{*}{-.75} & $(1.10)$ & (1.10) & \multirow{2}{*}{.63} & \multirow{2}{*}{.64} & \multirow{2}{*}{.17} & \multirow{2}{*}{.17} \\
\hline & & & & & $\left(1.0^{*}\right)$ & $\left(1.0^{*}\right)$ & & & & \\
\hline \multirow{2}{*}{ Ownership in exercise } & .62 & .68 & & -.71 & .69 & 80 & (.91) & (.91) & 25 & \\
\hline & .62 & .68 & -.68 &.$- / 1$ & .69 & .69 & $\left(1.0^{*}\right)$ & $\left(1.0^{*}\right)$ & $\begin{array}{c}.25 \\
(1.01)\end{array}$ & $\begin{array}{c}.25 \\
(1.01)\end{array}$ \\
\hline & .32 & .36 & -.19 & -.17 & .22 & .22 & .34 & .34 & $\left(1.0^{*}\right)$ & $\left(1.0^{*}\right)$ \\
\hline
\end{tabular}

Note. The upper triangle shows the results from the male group. The lower triangle shows the results for the female group. The values in parentheses are the standard deviations for each construct in each group. The asterisks by the female variances designates that they were fixed to 1.0 to set the scale for the construct. 
Table 4

Sample 3 Standardized, Unconstrained Variances and Correlations

\begin{tabular}{|c|c|c|c|c|c|c|c|c|}
\hline & \multicolumn{2}{|c|}{ Task-involving Climate } & \multicolumn{2}{|c|}{ Ego-involving Climate } & \multicolumn{2}{|c|}{ Caring Climate } & \multicolumn{2}{|c|}{ Commitment to Exercise } \\
\hline & 27-items & 12-items & 27-items & 12-items & 27-items & 12-items & 27-items & 12-items \\
\hline \multirow{2}{*}{ Task-involving Climate } & $(1.08)$ & $(1.05)$ & \multirow{3}{*}{$\begin{array}{c}.06 \\
(1.08) \\
\end{array}$} & \multirow{3}{*}{$\begin{array}{c}.13 \\
(1.08) \\
\end{array}$} & \multirow{2}{*}{.51} & \multirow{2}{*}{.48} & \multirow{2}{*}{.14} & \multirow{2}{*}{.12} \\
\hline & $(1.0 *)$ & $(1.0 *)$ & & & & & & \\
\hline \multirow{2}{*}{ Ego-involving Climate } & \multirow{2}{*}{.05} & \multirow{2}{*}{.13} & & & \multirow{3}{*}{$\begin{array}{c}-.10 \\
(1.04)\end{array}$} & \multirow{3}{*}{$\begin{array}{c}-.10 \\
(1.04)\end{array}$} & \multirow{2}{*}{-.08} & \multirow{2}{*}{-.09} \\
\hline & & & $\left(1.0^{*}\right)$ & $(1.0 *)$ & & & & \\
\hline \multirow{2}{*}{ Caring Climate } & \multirow{2}{*}{.47} & \multirow{2}{*}{.43} & \multirow{2}{*}{-.11} & \multirow{2}{*}{-.11} & & & \multirow{2}{*}{.02} & \multirow{2}{*}{.02} \\
\hline & & & & & $\left(1.0^{*}\right)$ & $\left(1.0^{*}\right)$ & & \\
\hline \multirow{2}{*}{ Commitment to Exercise } & \multirow{2}{*}{.14} & \multirow{2}{*}{.12} & \multirow{2}{*}{-.10} & \multirow{2}{*}{-.11} & \multirow{2}{*}{.02} & \multirow{2}{*}{.02} & $(.98)$ & $(.98)$ \\
\hline & & & & & & & $\left(1.0^{*}\right)$ & $\left(1.0^{*}\right)$ \\
\hline Means (Male) & 3.34 & 3.38 & 3.03 & 2.97 & 3.89 & 3.89 & 3.75 & 3.75 \\
\hline Means (Female) & 3.31 & 3.35 & 3.05 & 2.83 & 3.89 & 3.89 & 3.72 & 3.72 \\
\hline
\end{tabular}

Note: The upper triangle shows the results from the male group. The lower triangle shows the results for the female group. The values in parenthesis are the variances for each construct in each group. The asterisks by the female variances designates that they were fixed to 1.0 to set the scale for the construct. 
Table 5

Sample 1 Model Fit Statistics

\begin{tabular}{|c|c|c|c|c|c|c|c|c|c|c|c|c|}
\hline \multicolumn{2}{|c|}{ Model Description } & $\chi^{2}$ & df & CFI & NNFI & SRMR & RMSEA & $\begin{array}{l}\text { RMSEA } \\
90 \% \mathrm{Cl}\end{array}$ & $\Delta \chi^{2}$ & $\Delta d f$ & $p$-value & Tenable \\
\hline PMCEQ-27 items & Configural Model & 2163.738 & 554 & 0.837 & 0.825 & 0.076 & 0.076 & $.073-.080$ & & & & \\
\hline PMCEQ-17 items & Configural Model & 1014.383 & 269 & 0.883 & 0.87 & 0.059 & 0.074 & $.070-.079$ & & & & \\
\hline PMCEQ-12 items & Configural Model & 613.528 & 164 & 0.904 & 0.888 & 0.053 & 0.074 & $.068-.080$ & & & & \\
\hline 3-group model & Configural Model & 1025.645 & 213 & 0.939 & 0.922 & 0.051 & 0.087 & $.082-.093$ & & & & \\
\hline 3-group model & Weak Invariance & 1064.531 & 233 & 0.937 & 0.927 & 0.062 & 0.084 & $.079-.090$ & & & & Pass \\
\hline 3-group model & Strong Invariance & 1245.247 & 253 & 0.925 & 0.919 & 0.12 & 0.089 & $.084-.094$ & & & & Pass \\
\hline 3-group model & Homogeneity of Variance & 1290.492 & 273 & 0.923 & 0.923 & 0.118 & 0.086 & $.082-.091$ & 45.245 & 20 & 0.001022 & Pass \\
\hline 3-group model & Homogeneity of Means & 1299.317 & 281 & 0.925 & 0.923 & 0.119 & 0.085 & $.080-.090$ & 8.825 & 8 & 0.357273 & Pass \\
\hline
\end{tabular}

Note. The first three configural models were run separately to independently test model fit and factor loading for parcel development. The 3-group models included a model for each PMCEQ version ( 27 items,17 items, and 12 items). These three models' parameters were constrained to equality systematically. 
Table 6

Sample 2 Model Fit Statistics

\begin{tabular}{|c|c|c|c|c|c|c|c|c|c|c|c|c|c|}
\hline \multicolumn{2}{|r|}{ Model Description } & $\chi^{2}$ & df & $\mathrm{CFI}$ & NNFI & SRMR & RMSEA & $\begin{array}{l}\text { RMSEA } \\
90 \% \mathrm{Cl}\end{array}$ & $\Delta \mathrm{CFI}$ & $\Delta \chi^{2}$ & $\Delta \mathrm{df}$ & $\begin{array}{l}p- \\
\text { value }\end{array}$ & Tenable \\
\hline PMCEQ-27 items & Null Model & 5093.16 & 342 & & & & & & & & & & \\
\hline PMCEQ-12 items & Null Model & 4652.75 & 342 & & & & & & & & & & \\
\hline \multirow[t]{2}{*}{ PMCEQ-27 items } & Configural Model & 529.13 & 250 & 0.94 & 0.92 & 0.065 & 0.07 & $.061-.078$ & & & & & \\
\hline & $\begin{array}{l}\text { Configural Model with Own2 WITH } \\
\text { Own4 corr }\end{array}$ & 489.87 & 248 & 0.95 & 0.93 & 0.063 & 0.065 & $.056-.074$ & & & & & \\
\hline \multirow[t]{2}{*}{ PMCEQ-12 items } & Configural Model & 478.63 & 250 & 0.95 & 0.93 & 0.059 & 0.064 & $.055-.073$ & & & & & \\
\hline & $\begin{array}{l}\text { Configural Model with Own2 WITH } \\
\text { Own4 corr }\end{array}$ & 440.56 & 248 & 0.96 & 0.94 & 0.059 & 0.059 & $.050-.069$ & & & & & \\
\hline PMCEQ-27 items & $\begin{array}{l}\text { Weak Model with Own2 with } \\
\text { Own4 corr }\end{array}$ & 517.17 & 261 & 0.95 & 0.93 & 0.076 & 0.064 & $.055-.073$ & & & & & \\
\hline PMCEQ-12 items & $\begin{array}{l}\text { Weak Model with Own2 with } \\
\text { Own4 corr }\end{array}$ & 461.10 & 261 & 0.96 & 0.94 & 0.069 & 0.058 & $.048-.067$ & 0.00 & & & & PASS \\
\hline \multirow[t]{2}{*}{ PMCEQ-27 items } & $\begin{array}{l}\text { Strong Model with Own2 WITH } \\
\text { Own4 corr }\end{array}$ & 605.15 & 274 & 0.93 & 0.91 & 0.083 & 0.072 & $.063-.080$ & 0.02 & & & & \\
\hline & Strong Model with RIVAL int freed & 579.16 & 273 & 0.94 & 0.92 & 0.078 & 0.069 & $.060-.077$ & 0.01 & & & & PASS \\
\hline \multirow[t]{2}{*}{ PMCEQ-12 items } & Strong Model & 543.87 & 274 & 0.94 & 0.93 & 0.077 & 0.065 & $.057-.074$ & 0.02 & & & & \\
\hline & Strong Model with RIVAL int freed & 517.59 & 273 & 0.95 & 0.94 & 0.072 & 0.062 & $.053-.071$ & 0.01 & & & & PASS \\
\hline \multirow[t]{2}{*}{ PMCEQ-27 items } & Homoegeneity of Variances & 612.46 & 278 & 0.93 & 0.91 & 0.101 & 0.071 & $\begin{array}{l}.062- \\
.0779\end{array}$ & & 33.30 & 5 & 0.000 & \\
\hline & $\begin{array}{c}\text { Homoegeneity of Variances, Ego } \\
\text { Variance Freed }\end{array}$ & 584.69 & 277 & 0.94 & 0.92 & 0.089 & 0.068 & $.059-.076$ & & 5.53 & 4 & 0.237 & PASS \\
\hline \multirow[t]{2}{*}{ PMCEQ-12 items } & Homoegeneity of Variances & 555.54 & 278 & 0.94 & 0.93 & 0.104 & 0.065 & $.057-.074$ & & 37.95 & 5 & 0.000 & \\
\hline & $\begin{array}{l}\text { Homoegeneity of Variances, Ego } \\
\text { Variance Freed }\end{array}$ & 529.49 & 277 & 0.95 & 0.93 & 0.094 & 0.062 & $.053-.071$ & & 11.90 & 4 & 0.018 & PASS \\
\hline PMCEQ-27 items & Phantom Base & 579.16 & 273 & 0.94 & 0.92 & 0.078 & 0.069 & $.060-.077$ & & & & & \\
\hline PMCEQ-12 items & Phantom Base & 517.59 & 273 & 0.95 & 0.94 & 0.072 & 0.062 & $.053-.071$ & & & & & \\
\hline \multirow[t]{2}{*}{ PMCEQ-27 items } & Homogeneity of Means & 608.79 & 278 & 0.93 & 0.91 & 0.086 & 0.071 & $.063-.079$ & & 29.63 & 5 & 0.000 & \\
\hline & $\begin{array}{l}\text { Homogeneity of Means with Ego } \\
\text { Mean Freed }\end{array}$ & 583.13 & 277 & 0.94 & 0.92 & 0.078 & 0.068 & $.059-.076$ & & 3.97 & 4 & 0.410 & PASS \\
\hline \multirow[t]{2}{*}{ PMCEQ-12 items } & Homogeneity of Means & 546.77 & 278 & 0.94 & 0.93 & 0.078 & 0.065 & $.056-.073$ & & 29.19 & 5 & 0.000 & \\
\hline & $\begin{array}{c}\text { Homogeneity of Means with Ego } \\
\text { Mean Freed }\end{array}$ & 521.23 & 277 & 0.95 & 0.94 & 0.072 & 0.061 & $.052-.070$ & & 3.65 & 4 & 0.456 & PASS \\
\hline
\end{tabular}


Table 7

Sample 3 Model Fit Statistics

\begin{tabular}{|c|c|c|c|c|c|c|c|c|c|c|c|c|c|}
\hline \multicolumn{2}{|c|}{ Model Description } & $\chi^{2}$ & df & CFI & NNFI & SRMR & RMSEA & $\begin{array}{l}\text { RMSEA } \\
90 \% \mathrm{Cl}\end{array}$ & $\Delta \mathrm{CFI}$ & $\Delta \chi^{2}$ & $\Delta \mathrm{df}$ & $\begin{array}{l}p \text { - } \\
\text { value }\end{array}$ & Tenable \\
\hline PMCEQ-27 items & Null Model & 5131.22 & 182 & & & & & & & & & & \\
\hline PMCEQ-12 items & Null Model & 4536.23 & 182 & & & & & & & & & & \\
\hline PMCEQ-27 items & Configural Model & 198.88 & 118 & 0.98 & 0.97 & 0.061 & 0.042 & $.032-.052$ & & & & & PASS \\
\hline PMCEQ-12 items & Configural Model & 177.21 & 118 & 0.99 & 0.98 & 0.058 & 0.036 & $.025-.047$ & & & & & PASS \\
\hline PMCEQ-27 items & Weak Model & 183.29 & 127 & 0.99 & 0.98 & 0.062 & 0.034 & $.022-.044$ & 0.00 & & & & PASS \\
\hline PMCEQ-12 items & Weak Model & 163.89 & 127 & 0.99 & 0.99 & 0.058 & 0.028 & $.013-.039$ & 0.01 & & & & PASS \\
\hline PMCEQ-27 items & Strong Model & 179.02 & 135 & 0.99 & 0.99 & 0.062 & 0.029 & $.016-.040$ & 0.00 & & & & PASS \\
\hline PMCEQ-12 items & Strong Model & 159.46 & 135 & 0.99 & 0.99 & 0.059 & 0.022 & $.000-.034$ & 0.00 & & & & PASS \\
\hline PMCEQ-27 items & Homogeneity of Variances & 187.68 & 139 & 0.99 & 0.99 & 0.063 & 0.03 & $.018-.041$ & & 8.661 & 4 & 0.07 & PASS \\
\hline PMCEQ-12 items & Homogeneity of Variances & 165.24 & 139 & 0.99 & 0.99 & 0.059 & 0.022 & $.000-.034$ & & 5.783 & 4 & 0.22 & PASS \\
\hline PMCEQ-27 items & Homogeneity of Covariances & 187.84 & 145 & 0.99 & 0.99 & 0.064 & 0.028 & $.014-.038$ & & 0.156 & 6 & 1.00 & PASS \\
\hline PMCEQ-12 items & Homogeneity of Covariances & 166.29 & 145 & 1.00 & 0.99 & 0.06 & 0.02 & $.000-.032$ & & 1.043 & 6 & 0.98 & PASS \\
\hline PMCEQ-27 items & Homogeneity of Means & 178.53 & 149 & 0.99 & 0.99 & 0.064 & 0.023 & $.001-.034$ & & 9.311 & 4 & 0.05 & PASS \\
\hline PMCEQ-12 items & Homogeneity of Means & 157.58 & 149 & 1.00 & 1.00 & 0.06 & 0.012 & $.000-.027$ & & 8.706 & 4 & 0.07 & PASS \\
\hline
\end{tabular}




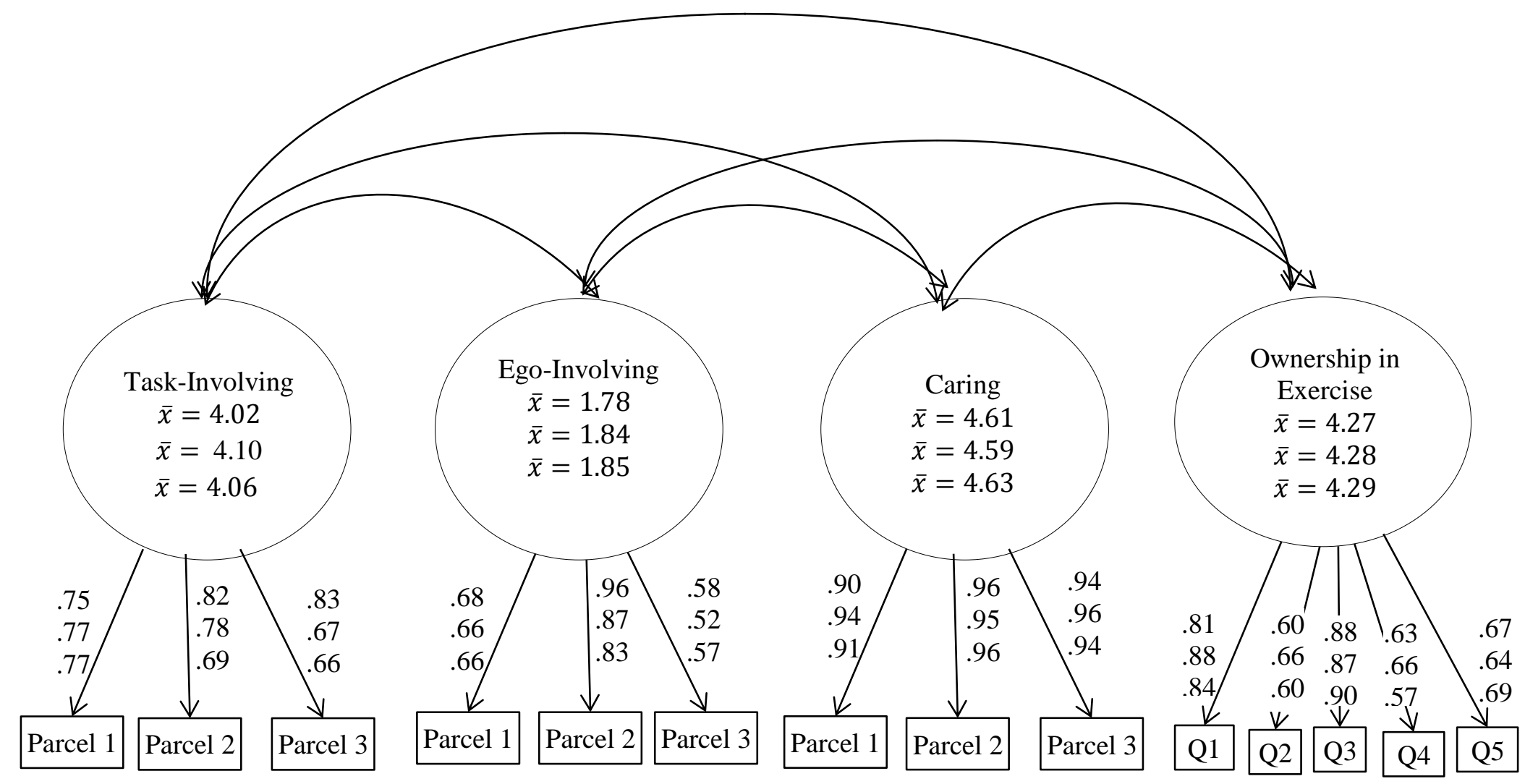

Figure 1. Sample 1 Factor Loadings \& Latent Means. The values are top to bottom: PMCEQ, PMCEQ-17, and PMCEQ-12. 